\title{
Medievalista
}

Online

$28 \mid 2020$

Número 28

redes e protagonistas ao tempo de D. Pedro

\section{O clero e as Cortes de 1361}

redes e protagonistas ao tempo de D. Pedro

The clergy and the Cortes of 1361: networks and protagonists in the time of Pedro

I of Portugal

\section{Hermínia Vasconcelos Vilar}

\section{(2) OpenEdition}

\section{Journals}

\section{Edição electrónica}

URL: http://journals.openedition.org/medievalista/3297

DOI: $10.4000 /$ medievalista.3297

ISSN: $1646-740 \mathrm{X}$

Editora

Instituto de Estudos Medievais - FCSH-UNL

\section{Edição impressa}

Paginação: 35-66

\section{Refêrencia eletrónica}

Hermínia Vasconcelos Vilar, «O clero e as Cortes de 1361», Medievalista [Online], 28 | 2020, posto online no dia 01 julho 2020, consultado o 23 março 2021. URL: http://journals.openedition.org/ medievalista/3297 ; DOI: https://doi.org/10.4000/medievalista.3297

Este documento foi criado de forma automática no dia 23 março 2021.

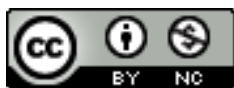

Mediavalista está licenciado com uma Licença Creative Commons - Atribuição-NãoComercial 4.0 Internacional. 
redes e protagonistas ao tempo de D. Pedro

O clero e as Cortes de 1361

redes e protagonistas ao tempo de D. Pedro

The clergy and the Cortes of 1361: networks and protagonists in the time of Pedro I of Portugal

Hermínia Vasconcelos Vilar

1 Quando as Ordenações Afonsinas tomaram forma ${ }^{1}$, os seus compiladores acharam por bem integrar, enquanto documentos representativos da relação entre reis e Igreja, os capítulos apresentados pelo clero nas Cortes de 1361, realizadas em Elvas. E intercalaram-nos entre, por um lado, a publicação dos acordos firmados em 1289 entre D. Dinis e o conjunto dos bispos das dioceses portuguesas, sob a égide e mercê da intervenção papal, em 1292, entre o mesmo monarca e quatro dos bispos responsáveis pelas dioceses do Porto, Guarda, Lamego e Viseu e, em 1309, com o Bispo de Lisboa João Martins de Soalhães e, por outro, os artigos estabelecidos entre D. João I e a cleresia do reino em 1390/91 e em $1427^{2}$.

2 Os documentos integrados nos primeiros títulos do segundo livro das Ordenações Afonsinas parecem, pois, corresponder a um grupo documental cuja importância, reconhecida pelos compiladores, justificava a sua fixação na memória legislativa que esta compilação representava. Firmados ao longo de um período que se estende desde 1289 a 1427, estes documentos têm em comum o facto de terem, na base, listas de agravos apresentadas pelos bispos ao papa, no caso da concordata de 1289 , ou apenas por alguns prelados ao rei como é o caso dos acordos parciais de 1292 e de 1309 ou pelo clero, aqui denominado de forma mais indistinta, como acontece nos documentos datados do reinado de D. Pedro I e de D. João I. Contudo, nada nos autoriza a pensar que os documentos coligidos compreendam a totalidade dos agravos apresentados durante estas décadas. Nada nos é dito, aliás, sobre os critérios subjacentes a esta escolha nem mesmo sobre a existência ou não de outras listas de queixas aqui não consideradas.

3 Torna-se claro, contudo, que, para os compiladores, o acento é colocado no acordo, ou seja, na integração da resposta régia, pelo que os artigos apresentados o são em função dessa mesma resposta e não em função das situações que o clero pretendia ver 
corrigidas. Ou seja, o que as Ordenações Afonsinas fixaram foi, predominantemente, o texto que resulta da conjugação dos agravos com as respostas dadas pelos diferentes monarcas.

4 Sendo esta uma prática comum a outros reinos europeus desde, pelo menos, meados do século $\mathrm{XIII}^{3}$, a verdade é que a apresentação de listas de agravos não vale apenas pelo rol de queixas apresentadas e pelos que estas nos deixam entrever sobre o quotidiano das relações entre poderes e dos níveis de interferência mútua nas respectivas esferas de actuação, mas também pelo que reflectem de aceitação tácita da realeza como protagonista do espaço político e destinatário privilegiado das queixas eclesiásticas. Neste quadro, os agravos apresentados pelos bispos das dioceses portuguesas na Cúria, em 1268, parecem constituir uma excepção e não a regra. Em Portugal, tal como noutros reinos, os agravos eram, muitas vezes, enviados ou apresentados ao rei, fosse em contexto de Cortes, fosse em contexto específico de diálogo entre poderes.

5 No caso dos artigos de 1361, a sua apresentação terá sido feita no quadro das Cortes convocadas para Elvas por D. Pedro. Realizadas em Maio deste ano, numa localidade relativamente excêntrica, se tivermos em consideração os locais escolhidos para a realização destas reuniões em reinados anteriores, mas cuja escolha se poderá explicar pelos circuitos da itinerância régia ${ }^{4}$, as actas das Cortes de 1361 constituem um elemento documental privilegiado no quadro da documentação sobrevivente para os dez anos da governação de D. Pedro. A par dos capítulos gerais e especiais do povo e de dois artigos gerais da nobreza que surgem preservados, realçam-se os trinta e três artigos coligidos respeitantes ao clero ${ }^{5}$.

6 Assim, e apesar das referências a estas Cortes, dispersas por diferentes obras, vale a pena ainda reflectir sobre as razões subjacentes à apresentação destes capítulos e a importância que lhes foi conferida nas décadas seguintes e que explicam a sua inclusão nas Ordenações Afonsinas.

7 Desta forma, e sem propor encetar uma análise exaustiva do seu conteúdo, procuraremos realçar alguns aspectos que individualizam estes capítulos na comparação com os acordos estabelecidos no reinado de D. Dinis e também coligidos nas Ordenações, para, num segundo momento, reflectir sobre a conjuntura compreendida entre os anos finais do reinado de D. Afonso IV e os primeiros de D. Pedro, anos de transição e de passagem, nem sempre pacífica, entre dois reinados e no contexto dos quais, mais uma vez e à semelhança do que já tinha ocorrido algumas décadas antes, no final do reinado de D. Dinis, grupos e facções se definiram e dividiram em torno do monarca em exercício e do infante herdeiro.

8 Sobre este pano de fundo, os bispos são elementos cuja centralidade política oscila entre a representatividade de um grupo, nem sempre coeso e muito menos com identidade própria, e as trajetórias individuais realizadas em função de interesses e relações que em muito ultrapassam o campo eclesiástico ${ }^{6}$.

9 Assim, embora a apresentação destes capítulos nos reenvie para uma imagem de coesão entre membros do clero, aquela poderá não reflectir mais do que a partilha possível de um conjunto de preocupações por alguns membros cuja identificação nos escapa, contudo, por completo, se considerarmos apenas o texto das actas das Cortes.

10 Atender aos protagonistas episcopais para os anos que se estendem entre o final do reinado de D. Afonso IV e 1361 será, pois, também um dos objetivos deste trabalho, sem que tal implique qualquer pretensão de reconstituição detalhada de percursos ou 
carreiras, mas apenas uma reflexão sobre as redes e a importância do serviço na definição da amplitude dessas redes.

\section{Rei e clero no discurso das Cortes de 1361}

11 À semelhança das razões invocadas por seu pai para a convocação das Cortes de $1352^{7}$, também D. Pedro expressa, no preâmbulo com que inicia as actas sobreviventes da reunião de 1361, a sua preocupação com a correção dos agravamentos que os seus povos sofriam em virtude da acção dos oficiais régios e apresenta-a como uma das razões subjacente à realização destas Cortes de Elvas. E mencionava ainda que nessa vila se encontravam então os infantes, seus filhos, bem como o arcebispo de Braga, bispos, abades e priores além dos ricos homens e vários filhos de algo. Tal como é realçado por Armindo de Sousa ${ }^{8}$, para uma cronologia um pouco posterior, é bem possível que esta presença tão numerosa, a ser real, cedo se dispersasse após os primeiros dias de reunião. As negociações dos capítulos apresentados pelos concelhos implicavam, não raras vezes, um prolongamento temporal que nem sempre os representantes dos grupos dominantes estavam disponíveis nem interessados em acompanhar. No caso específico do clero, a sua presença nem sempre é atestada nas reuniões de Cortes, fruto, por um lado, da escassez documental e, por outro, de um efectivo distanciamento em relação a estas reuniões. Distanciamento que se saldaria por uma presença parcial ou limitada a alguns membros ou por uma participação limitada e curta no evoluir dos trabalhos.

No entanto, quando presente, é de supor que o clero se faria representar, tendencialmente, por membros do clero episcopal ${ }^{9}$, embora a identificação desses representantes raramente seja feita, o que é também o caso dos capítulos apresentados em 1361.

Silêncio que se estende ao conteúdo dos próprios artigos. Com efeito, o perfil de agravos, tal como foi fixado pelas actas das Cortes, reenvia-nos para um discurso genérico, alusivo às acções que o clero pretende ver condenar ou corrigir por parte do rei, mas sem que seja feita qualquer alusão específica a um espaço ou a figuras às quais se reportam as queixas. Opção também ela comum a todos os demais textos de acordos. Ou seja, o articulado é sempre estabelecido em função de um perfil genérico que aponta para um abuso ou para um desrespeito, sem indicar protagonistas nem vítimas.

E são a estes agravos, sem alusões individualizadoras de quem as pratica ou de quem as sofre, que os monarcas respondem.

De uma forma geral os capítulos apresentados ou melhor os artigos respondidos pelo rei em 1361 não parecem trazer grandes novidades quando comparados com os artigos incluídos nos acordos de 1289 e de 1292. Daí a tendência para concluir que o retomar e a longevidade dos temas em discussão entre realeza e clero, constitua o reflexo de uma prática continuada de desrespeito pelos compromissos anteriormente assumidos ${ }^{10}$.

No entanto, e sem questionar a continuidade dessas práticas, a questão que se deve colocar reside, também, na inevitabilidade ou não dessas práticas e logo das queixas que elas suscitam. Ou seja, mais do que reflexos de problemas conjunturais, os agravos apresentados pelo clero e respondidos por D. Pedro correspondem à modelação progressiva da actuação dos poderes em presença e à redefinição das respectivas esferas de actuação. E assim, da mesma forma que D. Pedro reitera princípios de diálogo 
e de respeito pelos direitos e liberdades religiosas sem questionar ou obstaculizar de forma clara a actividade dos seus oficiais, também prelados e membros do clero se vêem obrigados a reiterar, de forma recorrente, a necessidade de acatar e de respeitar os privilégios e as isenções eclesiásticas.

17 O discurso vertido nas respostas régias reflecte assim o equilíbrio possível entre poderes e os limites implícitos da actuação régia e da reivindicação eclesiástica.

Contudo, isto não impede a constatação da continuidade das temáticas inerentes aos agravos. Continuidade que se estende também à argumentação utilizada pelo rei, bem como à noção de uma articulação temporal entre estes capítulos apresentados em 1361 e os agravos avançados em datas anteriores. Ou seja, tanto os representantes do clero como o próprio monarca estão cientes da continuidade temporal das temáticas abordadas e do retomar de velhos problemas que viram já soluções de consenso e de concórdia anteriormente estabelecidas e depois não cumpridas.

19 As referências feitas a cartas assinadas no reinado de D. Dinis e de D. Afonso IV bem como as menções explícitas ao acordo de 1289 pressupõem o recurso a estes textos pelas partes em presença, tanto na altura da redacção dos capítulos como no momento de elaboração das respostas, sendo esgrimidas como fontes de legitimidade para caucionar comportamentos ou como limites à actuação de oficiais e nobres, cujos comportamentos, quando desrespeitadores desses mesmos limites, recaíam na esfera do condenável.

E daí que a invocação do acordado entre monarcas e clero não fosse um exclusivo do discurso régio. Também os representantes do clero faziam eco desses acordos como elemento de fixação de uma prática que cabia preservar, ou seja, filiavam no desrespeito pelo acordado a justificação para a apresentação de queixas, assumindo assim que o estabelecido tinha correspondido a momentos de negociação e de fixação de equilíbrios. Os artigos $9^{\circ}$ e $15^{\circ}$ são particularmente elucidativos a este respeito ${ }^{11}$. Neles, os representantes do clero invocam, de forma clara, as cartas de D. Dinis e o artigo "que antre El rey e a Igreja he prometido e jurado em Corte de Roma" a propósito dos atentados praticados pelos corregedores do rei no que respeitava às jurisdições exercidas pelo clero nos seus espaços coutados ${ }^{12}$.

21 Mas, ao contrário do que ficou fixado no texto de 1289 vertido nas Ordenações Afonsinas, em 1361 D. Pedro não se limitou a assumir compromissos futuros de respeito pelo estabelecido ou a negar tais práticas, como seu avô D. Dinis fez, através dos seus procuradores. As respostas de 1361 são bastante mais elaboradas e denotam uma preocupação em assegurar o cumprimento das disposições régias, dentro dos limites de respeito por alguns privilégios da Igreja.

22 Assim, se bem que o rei assuma o respeito pelos direitos e liberdades da igreja, fá-lo sem deixar de afirmar o espaço de actuação dos seus oficiais no quadro do disposto em cartas e legislação anterior e exigindo documentos que comprovassem os abusos praticados pelos mesmos e dos quais os clérigos se queixavam.

23 Estas queixas incidiam, na sua maioria, sobre a intervenção dos oficiais ligados ao exercício da justiça e ao desrespeito pela aplicação do foro eclesiástico, sobre os abusos praticados pela nobreza e família real no exercício do direito de aposentadoria e sobre a desconsideração pelas sentenças eclesiásticas e mesmo pelas normas religiosas que muitos oficiais régios evidenciavam na sua actuação. 0 artigo $31^{\circ}$ faz eco dessas práticas ao relatar que os representantes régios não hesitavam em realizar reuniões e 
audiências aos domingos e dias de festas nas igrejas e nos seus adros, ignorando o carácter sagrado destes dias dedicados à oração. E, quando admoestados, ameaçavam prelados e vigários escarnecendo das penas com que eram ameaçados ao declararem que "a escumunham nom brita osso e que o vinho nom amargua ao escumungado" 13 . Queixa face à qual o rei se limitou a exortar as suas justiças a que respeitassem os ofícios divinos e se abstivessem de causar conflitos com os clérigos. Recomendação bastante genérica, fundamentada mais na capacidade de acatamento dos oficiais do que na condenação explícita dos comportamentos.

Algo de semelhante acontece com o artigo seguinte, no qual o clero se referia ao chamado beneplácito régio, queixando-se do atraso na publicação das cartas papais em virtude da ordenação régia que estabelecia a obrigatoriedade de uma prévia aprovação por parte do rei, situação que suscitava o envio de repreensões papais para as quais os bispos portugueses não tinham resposta. Face a este agravo, D. Pedro limitou-se a responder "Que nos mostrem estes rrescriptos e lletras e ve llas emos e mandaremos que sse provyquem pela guyssa que devem" ${ }^{14}$, ignorando desta forma o pedido feito para a revogação da referida ordenação.

Centrados, como já referimos, na acção dos oficiais ligados à justiça, no desrespeito pelo disposto pelo direito canónico e nos abusos protagonizados pelos ricos homens, os capítulos de 1361 parecem ignorar temáticas presentes em 1289, com realce para os problemas decorrentes das eleições episcopais e da intervenção indevida do rei nestes processos, bem como do exercício do direito de padroado ou mais especificamente do exercício da capacidade de confirmação dos apresentados pelo bispo.

Estas ausências podem ser consideradas, à partida, aleatórias ou tidas como resultados das escolhas feitas pelos representantes do clero ou pelos compiladores das respostas sobre o que seriam os problemas mais prementes em 1361 e que deveriam ser, assim, sujeitos ao registo escrito. Contudo, ausências como as referidas acima podem também reflectir novos equilíbrios entre os protagonistas dos processos de designação episcopal, com a crescente capacidade de intervenção papal no sistema de escolha e o implícito reconhecimento do espaço de intervenção real ${ }^{15}$. Desta forma, a capacidade de reivindicação dos bispos em 1268 e vertida na concordata de 1289 talvez não fosse a mesma em 1361, nomeadamente no que se referia à possibilidade de controlar a capacidade de intervenção do rei nos processos de designação, sobretudo quando estes decorriam no âmbito capitular. Até porque desde o final do século XIII que o papado tinha também vindo a desenhar e a circunscrever um novo espaço para a sua intervenção.

À partida, os agravos apresentados em 1361 podem ser encarados como reflexo de um mal-estar latente que os representantes do clero fazem chegar ao rei nestas Cortes convocadas quatro anos após o início do seu reinado. Para alguns autores, os artigos apresentados expressam os problemas derivados de uma relação conflituosa entre D. Pedro e o clero ${ }^{16}$. No entanto esta poderá ser uma leitura parcial.

28 A apresentação de agravos a um rei, sobretudo em contexto de Cortes, pode não ser sinónimo obrigatório de mal-estar ou de conflito latente, mas antes da capacidade de repensar equilíbrios e obter compromissos.

Para aferir vale a pena reflectir sobre o lugar ocupado por estas Cortes no contexto do reinado de D. Pedro e determo-nos sobre os indícios documentais de um relacionamento. 


\section{Rei e clero na chancelaria}

Num reinado marcado por uma acentuada escassez documental, o ano de 1361 caracteriza-se pela existência de um volume assinalável de documentação, dirigida a diferentes prelados do reino ${ }^{17}$. No decurso do mês de Maio e estando o rei em Elvas, a chancelaria de D. Pedro exarou, pelo menos, seis cartas dirigidas aos bispos de Lamego e de Silves e ao arcebispo de Braga. Datadas de entre 21 e 27 de Maio, será lícito pressupor que a sua redacção foi paralela à realização das Cortes e visaram recompensar os ou alguns dos bispos presentes. No caso, tiveram como destinatários Durão Lourenço de Lamego, Vasco Lourenço de Silves e Guilherme de La Garde, arcebispo de Braga.

1 Ao primeiro, o rei confirmou os privilégios detidos pelo bispo e cabido ainda a 12 de Maio, estando em Évora ${ }^{18}$ e cerca de dez dias mais tarde, a 23 de Maio, reforçou o disposto em cartas anteriores de seu pai e avô sobre a proibição de aposentadoria nos coutos, celeiros, honras e lugares do bispo e do cabido de Lamego ${ }^{19}$. Cartas feitas a pedido de D. Durão, delas foram elaboradas cópias guardadas no arquivo da diocese ${ }^{20}$, além das registadas na chancelaria.

2 Também ao bispo e ao cabido de Silves D. Pedro confirmou privilégios e liberdades em

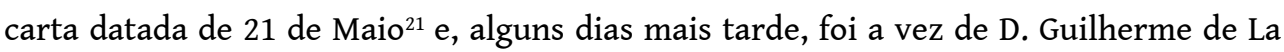
Garde, arcebispo de Braga, ser agraciado com o favor régio.

Nas vésperas da sua transferência para Arles ${ }^{22}$, Guilherme de La Garde foi o destinatário de quatro cartas, todas elas datadas de 27 de Maio e através das quais o rei lhe reconheceu a posse de privilégios e direitos, como foi o caso das competências exercidas pelos tabeliães, nomeados pelo arcebispo, em todo o território do arcebispado. Nesta carta, D. Pedro ordenou o retorno aos termos dispostos pelo pai e anteriores ao embargo colocado por ele próprio ${ }^{23}$. E dispôs o mesmo no que se refere ao exercício de jurisdição sobre Braga e outros lugares, a qual lhe tinha sido tomada a seu mandado ${ }^{24} \mathrm{e}$ sobre Provesende, nas condições em que o arcebispo a exercia, antes do disposto por seu pai e isto enquanto fosse sua mercêe $\hat{e}^{25}$.

Desta forma, e através destas cartas, D. Pedro fazia alusão à existência de conflitos anteriores e de sentenças que teriam julgado a apropriação do exercício da jurisdição por parte do rei. Por um lado, D. Pedro aludia, possivelmente, às consequências inerentes ao "chamamento geral" realizado por seu pai para confirmação do exercício da jurisdição cível e crime por parte de diferentes senhores e aos duros conflitos travados entre D. Afonso e o arcebispo D. Gonçalo Pereira sobre a amplitude da jurisdição exercida pelo arcebispo em Braga e especificamente em torno da legitimidade de nomeação dos tabeliães ${ }^{26}$, mas, por outro, aludia aos seus próprios mandados, os quais teriam resultado na apropriação de direitos que agora o rei devolvia. Mandados que incidiriam sobre o âmbito da jurisdição exercida pelo arcebispo em Braga, questão à qual D. Pedro retornaria nos anos seguintes, numa altura em que também a jurisdição episcopal sobre o Porto se mantinha em discussão ${ }^{27}$.

No que se refere a esta diocese, logo no início do reinado, D. Pedro dirigiu ao bispo do Porto uma carta de reconhecimento de privilégios ${ }^{28}$, mantendo com o prelado uma relação aparentemente pacífica, não obstante os problemas latentes sobre o senhorio da cidade ${ }^{29}$. 
36 A sucessão de cartas dirigidas a bispos e redigidas durante os meses centrais de 1361, surge assim articulada com a realização das Cortes.

À semelhança de cronologias anteriores, tanto o rei como os prelados parecem aproveitar a realização destas reuniões para obterem novas cartas de confirmação de privilégios ou para verem corrigidos aspectos menos claros do funcionamento da justiça régia e do exercício da jurisdição eclesiástica. Mas a elaboração destas cartas também atesta o que já tem vindo a ser realçado sobre a amplitude dos intercâmbios e das manobras políticas desenvolvidas dentro e fora das reuniões, ou seja, os representantes do clero e da nobreza, tal como os procuradores dos povos, mas talvez com mais realce para os primeiros, não se deslocavam à localidade onde as Cortes se realizavam apenas para apresentar os seus agravos sob a forma de capítulos. Tão ou mais importante era a negociação paralela entrevista na promulgação coeva de cartas ou de privilégios.

Assim, as cartas exaradas nestes dias de Maio e Junho parecem completar o acordo estabelecido em torno dos artigos apresentados nas Cortes, demarcando o âmbito do exercício das jurisdições e privilégios. Mas o que parece ressaltar destas cartas é também a referência constante à situação existente no reinado de seu pai D. Afonso IV.

Aludindo muito possivelmente aos efeitos e às consequências derivadas do lançamento do já mencionado "chamamento geral" e às sentenças que resultaram da obrigação de demonstração por parte dos senhores dos documentos que fundamentavam a posse de jurisdição cível e crime, D. Pedro menciona em quase todas os documentos o disposto pelo pai, ora para acatar e confirmar, ora para questionar ou mesmo negar.

40 É o que parece acontecer com uma das cartas já referida e dirigida a D. Guilherme de La Garde, arcebispo de Braga, sobre a jurisdição exercida sobre Provesende e na qual o rei lhe permitia regressar ao exercício da sua jurisdição nos termos anteriores à apropriação feita pelo pai ${ }^{30}$.

41 Aliás a invocação do disposto por Afonso IV e o contraponto com o estabelecido nos anos do seu governo não se limita às cartas exaradas em 1361. Desde os primeiros anos, ou seja, logo desde 1357, que D. Pedro responde a solicitações dos bispos em exercício sobre o exercício de jurisdições e sobre a continuidade ou não da aplicação das regras dispostas por Afonso IV.

42 Logo em Agosto de 1357, D. Pedro respondeu a uma solicitação de D. Durão, bispo de Lamego, sobre a jurisdição episcopal nos coutos de Lamego, Parada, Vila Seca e outros lugares $^{31}$. D. Durão pedia ao rei o regresso à situação anterior à sentença favorável obtida por Afonso IV sobre a jurisdição episcopal nestes locais, a qual tinha impedido o bispo de a exercer nos termos do que acontecia anteriormente. Pedido que D. Pedro autorizou, ressalvando que o fazia apenas em vida do bispo e não embargando a sentença obtida pelo monarca anterior. Desta forma, após a morte de D. Durão, todos os direitos reverteriam para o rei nos termos anteriores.

No mesmo sentido foi a carta exarada em Outubro do mesmo ano, na qual D. Pedro outorgou ao bispo de Tui o padroado da igreja de Santo Estêvão de Valença, mencionando que o fazia para impedir conflitos entre ele e o bispo sobre a posse desta igreja que D. Afonso IV tinha reivindicado e, embora D. Pedro afirmasse possuir provas concretas dos seus direitos sobre esta igreja, fazia dela doação em virtude do muito serviço prestado pelo bispo e pela igreja de Tui ${ }^{32}$. 
Também no ano seguinte, mas em Junho, D. Pedro respondeu a uma solicitação de D. Lourenço Martins, bispo de Coimbra, no sentido de confirmar a amplitude e a legitimidade da jurisdição exercida pelo bispo e cabido em vários locais e coutos. A carta exarada deteve-se no elenco pormenorizado dos diferentes locais, identificando a forma como devia ser aplicada em cada lugar, ressalvando que a doação seria válida enquanto sua mercê fosse e sem prejuízo de si nem dos seus sucessores ${ }^{33}$.

E também ao bispo e igreja da Guarda confirmou privilégios e direitos em Abril de $1360^{34}$.

À partida, todas estas cartas poderiam não representar mais do que a preocupação legítima dos prelados em verem confirmados os seus privilégios no início de um novo reinado ${ }^{35}$. Contudo, mais do que essa preocupação, o que estas cartas também parecem reflectir são tentativas de alteração ou de reversão, parcial ou integral, de processos e sentenças recentes sobre o exercício jurisdicional, aproveitando a mudança de reinado e as oscilações nas alianças. E D. Pedro parece também aproveitar essa mudança para alterar, circunstancialmente, algumas situações e reconfirmar outras, alargando assim o espaço de intervenção do novo rei.

Aliás, não o fará apenas em favor do clero episcopal. Também ao convento e abade de Alcobaça, por exemplo, exarou uma carta de resposta ao pedido feito pelo abade sobre o couto de Beringel, cuja jurisdição lhes teria sido retirada por Afonso IV, após contenda com o concelho de Beja. E invocava então o abade que sempre tinha sido sua pretensão pedir a revisão da sentença, mas que, em virtude da peste e de outras situações, o não tinha feito até agora. Face a este pedido, de novo D. Pedro altera a situação anterior, restituindo ao abade a capacidade de exercício da jurisdição cível e crime, bem como todos os direitos reais sobre o couto de Beringel ${ }^{36}$.

Não pretendendo reflectir sobre a política mais geral de D. Pedro a propósito do exercício das jurisdições senhoriais, a verdade é que a acumulação de pedidos de revisão e alteração de situações logo nos primeiros anos de governo e reportadas a sentenças ou decisões tomadas no reinado anterior não pode ser entendida à margem do processo de transição entre reinados, reforçada pelo facto de os últimos anos do governo de Afonso IV terem sido marcados pela conflitualidade com o infante herdeiro.

Esta crise que parece repetir, em vários aspectos, um conflito similar ocorrido entre 1319 e 1324 entre D. Dinis e o então infante Afonso, surge aclarada num conjunto de documentos de concórdia firmados entre 1355 e 1356, os quais merecem uma pequena análise no quadro das relações com o clero.

50 Estas cartas exaradas entre Agosto de 1355 e Janeiro de 1356 reúnem os compromissos realizados, individualmente, pelo infante, pelo rei e pela rainha, a lista de mercês concedidas pelo rei ao infante e o outorgamento feito pelo rei dessas mesmas doações, bem como as cartas de procuração dos representantes do rei e do infante. Juntam-se a este conjunto duas cartas abertas de D. Pedro, uma dirigida aos mestres das ordens militares de Avis e de Santiago e ao prior do Hospital e outra a todos os concelhos do reino solicitando a confirmação do acordado e o compromisso em cumprir o disposto ${ }^{37}$.

De entre a numerosa informação colhida nestes documentos, vários autores têm ressaltado a lista de vassalos que, de um e de outro lado, asseguravam o respeito do rei e do infante pelo cumprimento do estabelecido. A partir dos nomes dos doze vassalos do infante, bem como dos nomes dos doze vassalos indicados pelo rei, desenham-se 
alianças e apoios e perfilam-se divisões entre linhagens no apoio ao monarca ou ao jovem infante.

52 Mas, a par dessas identificações que permitiram, por exemplo, a Bernardo Vasconcelos e Sousa afirmar o possível domínio político do jovem infante face ao rei ${ }^{38}$, domínio que lhe teria permitido negociar e obter do rei mercês e favores que o seu próprio pai não tinha obtido quando era ainda um infante rebelde, a verdade é que o conjunto destes documentos nos permite ainda entrever aspectos vários do processo de negociação.

Os motivos tradicionalmente avançados para explicar este confronto entre Afonso e Pedro residem na morte violenta de D. Inês, às mãos de alguns fidalgos próximos do rei, em Janeiro de 1355. E com efeito, essa morte é assinalada e referida como estando na origem do "desvayro" havido entre o rei e seu filho. Mas aos efeitos decorrentes desta morte, o texto refere ainda "alguas outras cousas que des entom aaca recrecerom". E nas cartas enviadas por D. Pedro, tanto aos mestres das ordens militares como aos concelhos, o infante limitar-se-á a invocar "os desvairos que antre nos recreçerom sobre alguas cousas", não fazendo então qualquer menção à morte de D. Inês.

54 Assim, de uma forma ou de outra, a morte da Castro terá acelerado um movimento de revolta do infante, cujo protagonismo político se tinha, contudo, vindo a acentuar já desde o início da década de 1350, mesmo no contexto dos equilíbrios políticos peninsulares ${ }^{39}$.

55 A reivindicação do exercício da justiça pelo infante, é um dos indícios mais presentes desse protagonismo e da amplitude do que estava em causa.

56 As primeiras cartas referem-se à aceitação e juramento pelas partes das condições acordadas. O infante jurou a 5 de Agosto em Canaveses, onde então sua mãe se encontrava, mas a partir daí passou a estar em Braga, nos paços do arcebispo, e aí exarou todas as restantes cartas. Já Afonso IV jurou as condições em S. Francisco de Guimarães a 14 de Agosto, mas a partir desta data permaneceu no Porto, nos paços do bispo. Enquanto isto, a rainha D. Beatriz, presente tanto em Canaveses como em Guimarães, parece também ela ter-se dirigido ao Porto, onde, no mosteiro de S. Domingos, se comprometeu, a 20 de Agosto, a respeitar as condições estabelecidas.

Ressalta assim, numa primeira leitura, o deambular dos diferentes protagonistas, sem que nunca rei e infante se encontrem face a face. E numa segunda leitura, ressalta o facto de quase todos os juramentos ou actos de registo coincidirem com espaços religiosos, nomeadamente mosteiros mendicantes de Guimarães e do Porto, mas também paços episcopais das duas cidades que eram então e ainda senhorios episcopais, apesar dos conflitos que tinham marcado as décadas anteriores.

Guilherme de La Garde, arcebispo de Braga, não se limitará aliás a albergar o infante. A sua presença é referida amiúde no texto, a par da rainha e enquanto testemunha dos compromissos assumidos. Já no caso do bispo do Porto, o rei parece limitar-se a ocupar os seus paços, pelo menos nos momentos de redacção e de registo documental, facto que se poderá ter ficado a dever ao facto desta diocese se encontrar num processo de transição entre o governo de Pedro Afonso e de Afonso Pires, nomeado em Outubro de $1355^{40}$.

59 O deambular assim desenhado pelo rei e pelo infante, sem que qualquer encontro entre eles se efective, pode reflectir a situação tensa ainda vivida. Da mesma forma que a fixação de Afonso no Porto e de Pedro em Braga pode corresponder ao resultado das 
campanhas militares encabeçadas pelo infante contra o Entre-Douro e Minho, Trás-osMontes e mesmo contra a cidade do Porto, nos primeiros meses de 1355.

Um outro aspecto que ressalta da leitura destes primeiros documentos é a presença e a importância da intervenção da rainha D. Beatriz em todo este processo. D. Pedro afirma, de forma repetida, que o compromisso de tréguas que assume se deve ao pedido de sua mãe, jurando, tal como é descrito, sobre os Santos Evangelhos e a cruz que se encontrava nas mãos da rainha, enquanto o rei jurará sobre os Evangelhos e a cruz que se encontrava nas mãos de D. Guilherme, arcebispo de Braga. Aliás o acordo identifica, desde o início, a rainha, bem como o arcebispo D. Guilherme, como os responsáveis pelo estabelecimento da composição e confere o papel central que lhes é devido no desenrolar do processo.

Mas o que parece igualmente retirar-se da leitura dos primeiros documentos é o aparente estatuto de igualdade que o texto reconhece aos dois protagonistas.

Tal como refere Bernardo Vasconcelos e Sousa, o exercício da justiça bem como do poder terão sido partilhados entre esta data e a morte do $\mathrm{rei}^{41}$. A aparente igualdade que ressalta da leitura destes textos e que é formalizada na repetição integral dos cerimoniais de juramento, no reconhecimento da validade dos respectivos selos de validação das cartas, nas lógicas semelhantes de preservação das cópias produzidas e guardadas nos respectivos arquivos, nos processos de designação dos vassalos que assumiriam os compromissos em nome dos dois protagonistas, no próprio exarar de cartas em paralelo - tal como a carta dirigida aos concelhos por D. Pedro deixa entrever, ao mencionar que uma carta semelhante de convocatória dos procuradores dos concelhos para virem jurar os acordos, tinha já sido feita por seu pai -, sai reforçada pelo texto que formaliza a entrega do exercício da justiça ao infante.

Em todo este processo ressaltam duas figuras do clero episcopal: D. Guilherme de La Garde, arcebispo de Braga e Afonso Pires, bispo do Porto. Figuras que veremos serem agraciadas, o primeiro ainda no contexto das Cortes, o segundo, tal como já referimos, numa carta logo no início do reinado e, mais tarde, em 1362. Duas figuras centrais no conjunto do clero episcopal português ou não fossem estes dois bispos os senhores das respectivas cidades.

\section{Bispos e serviço régio: uma dicotomia central?}

64 Tal como acima referimos, não sabemos ao certo quais os prelados presentes nas Cortes de 1361. É possível, dada a importância dos artigos apresentados, que uma parte significativa desse grupo tenha estado presente ou se tenha feito representar. É mesmo possível supor, como foi mencionado, que as cartas exaradas em 1361 correspondam a presenças efectivas dos prelados em causa. Mas pouco mais é possível afirmar.

Tal não impede, bem pelo contrário, que possamos olhar para o conjunto de eclesiásticos que estavam, por estes anos, no governo das dioceses portuguesas e que, de uma forma ou de outra, fizeram eco do mal-estar que dominava as relações com a realeza e com a nobreza.

E uma das características que ressalta deste grupo, se tomarmos o ano de 1361 como referencial, reside no número de bispos nomeados durante a década de 1350, e logo, contemporâneos dos últimos anos do reinado de Afonso IV e, em alguns casos, da crise que marcou os anos de 1355-1356. 
therme de la Garde de Braga, nomeado em 1349 e Afonso Pires do Porto, confirmado nos últimos meses de $1355^{42}$, são dois dos casos já mencionados, aos quais se juntam Durão Lourenço de Lamego, João Martins de Viseu, João Gomes de Chaves de Évora e Vasco de Silves ${ }^{43}$. Este facto, embora possa parecer fortuito, coloca-os como testemunhas de um processo de transição política e de reconfiguração de alianças em torno dos dois protagonistas régios.

A estes junta-se um pequeno grupo de prelados nomeados ou transferidos entre dioceses, em 1358, e cujos governos se estendem até 1363 ou 1364, como é o caso de Lourenço Martins de Lisboa, Pedro Gomes de Coimbra e Gil Viana da Guarda ${ }^{44}$. No entanto, todos estes exerciam cargos na hierarquia eclesiástica nos anos anteriores, fosse como bispos de outras dioceses fosse na estrutura capitular, como era o caso de Gil de Viana, deão da Guarda antes da sua nomeação para bispo ${ }^{45}$.

Se alargarmos um pouco o âmbito de análise e olharmos para o conjunto de prelados responsáveis pelas dioceses portuguesas, entre 1355 e 1361, um curto espaço de tempo sem dúvida e que não permite grandes conclusões, outros dados parecem ressaltar e prendem-se com a importância das transferências e com as linhas descritas por estes processos de transferência.

70

Com efeito, e sem particular admiração, tendo em conta a crescente importância da intervenção papal nas designações episcopais, assistimos a um número importante de transferências realizadas, aparentemente, por iniciativa do Papa. Estas parecem afectar particularmente as dioceses de Braga, Lisboa e Coimbra. A par dos clérigos estrangeiros que foram transferidos de dioceses estrangeiras e que ocuparam, a título passageiro, lugares em dioceses portuguesas, como é o caso de Reginaldo de Maubernard em Braga, o que merece destaque são as transferências internas: entre 1358 e 1369 a diocese de Lisboa conhece dois bispos sucessivos que são transferidos a partir de Coimbra ${ }^{46}$. Esta diocese, por seu turno, também recebe dois prelados que vêm de diferentes dioceses: Lourenço Rodrigues, proveniente da Guarda, onde era bispo, e Pedro Gómez Barroso, prelado de Siguença, os quais serão sucessivamente transferidos para Lisboa. Se ampliarmos a cronologia, vemos que também Vasco Fernandes, bispo de Coimbra entre 1364 e 1371, transitou da Guarda para Coimbra e daqui para Lisboa ${ }^{47}$. Em outras dioceses, mantém-se a tendência para a escolha de membros do próprio cabido, como aconteceu com Durão de Lamego, anteriormente cónego dessa diocese, com Gil de Viana, deão da Guarda e com João Martins deão, também, de Viseu.

71 Os trajectos desenhados pelas transferências reforçam assim a centralidade de Lisboa enquanto destino privilegiado do cursus honorum episcopal entre dioceses portuguesas e um reforço das hierarquias internas já entrevistas em décadas anteriores. Em paralelo, a manutenção do cursus honorum entre cabido e prelazia parece manter-se, quando possível, em dioceses nas quais a pressão externa pela procura de benefícios era menor.

Os bispos das dioceses portuguesas destes anos parecem refletir nos seus trajectos, em alguns casos apenas parcialmente conhecidos, redes de diferente amplitude e constituição. Ao predomínio das relações curiais e dos percursos feitos na Cúria ou ao serviço do Papa, contrapõe-se uma aparente menor notoriedade do serviço régio. Embora alguns, como Lourenço Rodrigues /Martins de Barbudo se possam identificar como clérigos do rei nos anos anteriores ao reinado de D. Pedro e apesar de vermos Guilherme de la Garde e Afonso Pires na vanguarda do processo de estabelecimento dos acordos entre Afonso IV e o infante, a verdade é que nem a chancelaria régia nem os 
trajectos passíveis de serem estabelecidos permitem afirmar a presença de colaboradores próximos do rei à frente das dioceses portuguesas nestes anos ${ }^{48}$.

Facto que não deixa de ir ao encontro do já analisado por Armando Luís de Carvalho Homem no início dos anos 90 quando afirmava a queda assinalável de eclesiásticos no desembargo de D. Pedro ${ }^{49}$ e em particular a partir de 1361, ano de realização das Cortes de Elvas, bem como a perda de importância dos cargos tradicionalmente entregues a eclesiásticos. Mas mesmo para os anos anteriores, coincidentes com o início do reinado, a presença dos eclesiásticos parece limitada a alguns clérigos cujos trajectos não culminam com a obtenção de postos na estrutura episcopal, como é o caso de Mestre Gonçalo das "Decretais" ${ }^{50}$. Ou seja, o que parece assinalável para estes curtos anos do governo de D. Pedro é uma aparente dissociação entre o serviço régio prestado no desembargo e os detentores de cargos episcopais. É obvio que o preenchimento destes estava sempre dependente da existência de momentos de vacância, mas é também claro que quando estes se apresentam, os candidatos escolhidos não se caracterizam por trajectos de acentuado serviço régio.

Tal não significa que a retribuição do serviço prestado não estivesse entre as preocupações de D. Pedro ${ }^{51}$. O próprio rei se faz eco dessa preocupação em muitas das cartas exaradas, e podemos entrever nas doações feitas e, sobretudo, na reversão de determinadas sentenças uma preocupação com a recompensa da lealdade e do serviço, bem como uma tendência para acentuar a diferença com alguns dos aspectos da política de seu pai.

Por outro lado, esta aparente dissociação não impede a colaboração entre bispos e rei, tal como é atestada no relato feito por Fernão Lopes sobre a declaração feita por D. Pedro sobre o seu casamento com D. Inês em Junho de 1360, ou seja, no ano anterior à realização das Cortes. Uma das testemunhas chamada para confirmar a declaração foi o bispo da Guarda, D. Gil, mas outros bispos, como D. Lourenço de Lisboa, D. Afonso do Porto e D. João de Viseu, presenciaram esta declaração, dando o aval a esta declaração e pretensão de D. Pedro ${ }^{52}$.

No entanto, como também já foi realçado por Carvalho Homem, D. Pedro não deixará de retomar e mesmo de acentuar muitos dos aspectos da política anteriormente desenvolvida por seu pai, muito em particular a partir de 1361, quando uma nova reforma do Desembargo toma corpo e novas ordenações alteram os trâmites judiciais.

A questão, no que ao clero episcopal diz respeito, passa pela necessidade de entender a aparente menor importância do serviço régio entre o clero episcopal não como um indício da menor capacidade de intervenção do rei, mas como um indício da mudança na relação entre intervenientes no processo de designação episcopal, com realce para o papa e os monarcas. Ou seja, a multiplicação das situações que implicavam a intervenção papal nos processos de designação não diminuía a capacidade de intervenção régia, da mesma forma que o aumento da presença de clérigos estrangeiros em Portugal precipitaria muitos clérigos portugueses a integrarem os círculos mais próximos do rei e a dependerem dele para a obtenção de novos benefícios ${ }^{53}$. Mesmo que estes não fossem lugares na hierarquia episcopal.

Desta feita, que dizer sobre a importância destes artigos apresentados nas Cortes de 1361 pelo clero e que dizer deste clero episcopal?

Nomeados no decurso da década de 1350, muitos dos bispos governantes em 1361 tinham sido testemunhas da crise de 1355-56 e nela tinham participado de forma mais 
ou menos directa ou tinham, pelo menos, acompanhado a progressiva implantação do poder do infante nos últimos anos do reinado de D. Afonso IV. Herdeiros de sentenças que, promulgadas nos anos anteriores, tinham alterado as formas de exercício da jurisdição detida por muitos prelados nos seus coutos e em diversos lugares das suas dioceses, cedo muitos deles tentam alterar situações, aproveitando a mudança de reinado e de alguns dos protagonistas dos círculos políticos. E fazem-no, com maior ou menor êxito, através de esforços individuais que se saldam pela promulgação de cartas particulares onde o favor régio se formaliza e a recompensa do serviço surge como argumento central da outorga, ou através de pedidos gerais como são os artigos apresentados em 1361.

80 Ao contrário de outros anteriormente apresentados, os capítulos de 1361 não me parecem reflectir a existência de uma crise particular ou próxima, para lá da que resultava da necessidade de reavaliação recorrente dos equilíbrios políticos, mas antes uma tentativa de formalizar nas Cortes um conjunto de pedidos que resultavam da política prosseguida por Afonso IV e que os bispos de alguma forma tentam inverter em 1361.

81 Já para D. Pedro este aparente acordo poderá ter representado um ponto de chegada possível entre os interesses dos bispos e a reafirmação do poder régio, após uma crise, a qual mais uma vez tinha demonstrado a fragilidade inerente ao poder real em momentos de transição. Sem questionar a amplitude do exercício do poder real, D. Pedro concedia aos bispos a revisão de alguns abusos praticados pelos nobres, a garantia do respeito pelo foro canónico dentro dos limites do exercício da justiça que cabia ao rei, a isenção do pagamento ilegítimo de alguns tributos extraordinários, reafirmando, em muitos casos, o carácter temporário e excepcional destas doações, porque dependentes da mercê e do favor régios. Tal como em outros momentos, as Cortes assumiam-se como o palco de reequilíbrios e de afirmação dos discursos do(s) poder(es) em presença.

\section{BIBLIOGRAFIA}

Fontes

Fontes manuscritas

Lisboa, ANTT

- Cabido da Sé de Lamego, maço 3 de doações, cartas e mercês régias, n.․ e 10.

- Gavetas, Gaveta XIII, maço 5, noำ.

Fontes impressas

Chancelarias Portuguesas. D. Pedro I. Lisboa: Instituto Nacional de Investigação Científica, 1984.

Cortes Portuguesas. Reinado de D. Afonso IV (1325-1357). Lisboa: Instituto Nacional de Investigação Científica, 1982. 
Cortes Portuguesas. Reinado de D. Pedro I (1357-1367). Lisboa: Instituto Nacional de Investigação Científica, 1986.

COSTA, António Domingues de Sousa (ed.) - Monumenta Portugaliae Vaticana. I Súplicas dos pontificados de Clemente VI, Inocêncio VI e Urbano V. Braga/ Porto: Editorial Franciscana, 1968.

Innocent VI (1352-1362). Lettres secrètes et curiales, publiées ou analysées par Pierre Gasnault. Tome III, fascicule IV. Paris: Éd. de Boccard, 1968.

Livro I de Místicos de Reis, Livro II dos Reis D. Dinis, D. Afonso IV D. Pedro. Documentos para a História da Cidade de Lisboa. Lisboa: Câmara Municipal de Lisboa, 1947.

LOPES, Fernão - Crónica de D. Pedro. Lisboa: Imprensa Nacional-Casa da Moeda, 2007.

Ordenações Afonsinas, 2ª ed., livros I-V. Lisboa: Fundação Calouste Gulbenkian, 1998.

Estudos

AMBLER, S. T. - Bishops in the Political Community of England, 1213-1272. Oxford: Oxford University Press, 2017.

ARNAUT, Salvador Dias - A Crise Nacional Dos Fins Do Século XIV. I - A Sucessão de D. Fernando. Lisboa: Imprensa de Coimbra, 1960.

ARRANZ DE GUZMAN, Ana - "Reconstrucción y verificación de las Cortes castellano-leonesas: la participación del clero”. En La España Medieval 13 (1990) pp. 33-132.

CAETANO, Marcello - História Do Direito Português. Fontes- Direito Público (1140-1495), 2ª ed. Lisboa: Editorial Verbo, 1985.

CASTRO, José Osório da Gama e - Diocese e Districto da Guarda. Porto: [s.e.] 1902.

COELHO, Maria Helena da Cruz - "O arcebispo D. Gonçalo Pereira: um querer, um agir". in IX Centenário da Dedicação da Sé de Braga. Congresso Internacional. Actas, volume II/1 - A Catedral de Braga na História e na Arte (séculos XII-XIX). Braga: Universidade Católica Portuguesa, Faculdade de Teologia, Cabido Metropolitano e Primacial de Braga, 1990, pp. 389-462.

COSTA, Adelaide Millán - “Comunidades urbanas de senhorio eclesiástico; a divergente experiência das Cidades do Porto e de Braga". in Estudos em Homenagem ao Prof. Dr. José Marques. Vol. I. Porto: FLUP, 2006, pp. 77-85.

COSTA, Adelaide Pereira Millán da, “As mulheres de D. Pedro I. Branca de Castela, Constança Manuel e Inês de Castro”. in MENINO, Vanda Lourenço; COSTA, Adelaide Lopes Pereira Millán - A rainha, as infantas e a aia: Beatriz de Castela, Branca de Castela, Constança Manuel, Inês de Castro. Lisboa: Círculo de Leitores, 2012

CRUZ, António - "Os bispos senhores da cidade. II - de D. Pedro Salvadores a D. Vasco Martins". in PERES, Damião e CRUZ, António (eds.) - História da cidade do Porto. Vol. I. Porto: Portucalense Editora, 1962, pp. 184-248.

DENTON, J. H. - "The Making of the "Articuli Cleri" of 1316". The English Historical Review 101.400 (1986), pp. 564-595.

DIAZ IBÁNEZ, JORGE; FARELO, Mário - "Pedro Gómez Barroso, o jovem”. in FONTES, João Luis (dir); GOUVEIA, António Camões, ANDRADE, Maria Filomena e FARELO, Mário (coord.) - Bispos e Arcebispos de Lisboa. Lisboa: Livros Horizonte, 2018, pp. 345-351.

DOMINGUES, José - As Ordenações Afonsinas: três séculos de direito medieval [1211-1512]. Sintra: Zéfiro, 2008. 
EUBEL, Conradus - Hierarchia Catholica Medii Aevi sive Summorum Pontificum, S.R.E. Cardinalium, Ecclesiarum Antistitum Series: ab Anno 1198 usque ad annum 1431 perducta:et Documentis tabularii praesertim Vaticani collecta, digesta. Monasterii, 1935-1978.

FERREIRA, Monsenhor J. Augusto - Memórias Archeológico-Históricas da cidade do Porto. Braga: Livraria Cruz, 1923.

FREITAS, Eugénio Cunha e - "Os bispos senhores da cidade. III- de D. Pedro Afonso a D. Gil Alma". in PERES, Damião e CRUZ, António (eds) - História da cidade do Porto. Vol. I. Porto: Portucalense Editora, 1962, pp. 249-279.

GOMES, Jesué Pinharanda - História da Diocese da Guarda. Braga: [edição do autor] 1981.

HOMEM, Armando Luís de Carvalho - O Desembargo Régio (1320-1433). Porto: Instituto Nacional de Investigação Científica, Centro de História da Universidade do Porto, 1990.

HOMEM, Armando Luís de Carvalho - "Subsídios para o estudo da administração central no reinado de D. Pedro I". in HOMEM, Armando Luís de Carvalho - Portugal nos finais da Idade Média: Estado, Instituições, Sociedade Política. Lisboa: Livros Horizonte, 1990, pp. 63-107.

JONES, W. R. - "Bishops, Politics, and the Two Laws: The Gravamina of the English Clergy". Speculum 41:2 (1966), pp. 209-245.

LEITÃO, André de Oliveira - “Lourenço Rodrigues (ou Lourenço Martins de Barbudo)”. in FONTES, João Luis (dir); GOUVEIA, António Camões, ANDRADE, Maria Filomena; FARELO, Mário (coord.) Bispos e Arcebispos de Lisboa. Lisboa: Livros Horizonte, 2018, pp. 329-344.

LEITÃO, André de Oliveira; NORTE, Armando - "Vasco Rodrigues". in FONTES, João Luis (dir); GOUVEIA, António Camões, ANDRADE, Maria Filomena; FARELO, Mário (coord.) - Bispos e Arcebispos de Lisboa. Lisboa: Livros Horizonte, 2018, pp. 361-379.

LINEHAN, Peter - At the Edge of Reformation: Iberia before the Black Death. New York: Oxford University Press, 2019.

LINEHAN, Peter - The Spanish Church and the Papacy in the Thirteenth Century. Cambridge: Cambridge University Press, 2005.

LOUREIRO, Sara - "O conflito entre D. Afonso IV e o infante D. Pedro (1355-1356)". Cadernos do Arquivo Municipal, $1^{\mathrm{a}}$ série, 7 (2003), pp. 8-62.

MARQUES, A. H. de Oliveira - Portugal na Crise dos séculos XIV e XV. Vol. IV. Nova História de Portugal. Dir. Joel Serrão e A. H. de Oliveira Marques. Lisboa: Estampa, 1987.

MARQUES, A. H. de Oliveira; DIAS, João Alves - Atlas Histórico de Portugal e do Ultramar Português. Lisboa: Centro de Estudos Históricos, 2003.

MARQUES, José - “D. Afonso IV e as jurisdições senhoriais”. in Actas das II Jornadas Luso-Espanholas de História Medieval. Vol. IV. Porto: INIC, 1990, pp. 1527-1566.

MARQUES, José - “Igreja e poder régio". in A Génese do Estado Moderno no Portugal Tardo-medievo. Ciclo de conferências. Lisboa: Universidade Autónoma de Lisboa, 1999, pp. 217-256.

MACHADO, J.T. Montalvão - Itinerários de El-Rei D. Pedro (1357-1367) Lisboa: Academia Portuguesa de História, 1978.

MORUJÃO, Maria do Rosário - "Bispos em tempo de guerra: os prelados de Coimbra na segunda metade do século XIV". in A Guerra e a sociedade na Idade Média. Actas das VI Jornadas LusoEspanholas de Estudos Medievais, 2 vols. Coimbra: Sociedade Portuguesa de Estudos Medievais, 2009, vol. II, pp. 539-550. 
MUXAGATA, Ana Filipa Coelho - A Corte de D. Pedro I (1320-1367). Lisboa: Universidade de Lisboa, 2019. Dissertação de Mestrado.

O'CALLAGHAN, Joseph - “The Ecclesiastical Estate in the Cortes of Leon-Castille, 1252-1350". The Catholic Historical Review, 67.2 (1981), pp. 185-213.

PIMENTA, Cristina - D. Pedro I. Rio de Mouro: Círculo de Leitores, 2005.

SARAIVA, Anísio Miguel de Sousa - "O processo de inquirição do espólio de um prelado trecentista: D. Afonso Pires, bispo do Porto (1359-1372).” Lusitania Sacra, 2ª série, 13-14 (2001-2002), pp. 197-228.

SOUSA, Armindo de - As Cortes Medievais Portuguesas (1385-1490), 2 vols. Porto: Instituto Nacional de Investigação Científica, 1990.

SOUSA, Bernardo Vasconcelos e - D. Afonso IV. Lisboa: Círculo de Leitores, 2005.

SOUSA, Bernardo Vasconcelos e - “A Guerra Civil de 1355”. in A Guerra e a sociedade na Idade Média. Actas das VI Jornadas Luso-Espanholas de Estudos Medievais. Vol. II. Coimbra: Sociedade Portuguesa de Estudos Medievais, 2009, pp. 393-407.

TABBAGH, Vincent - Les Évêques dans le Royaume de France au XIVe Siècle. Dijon: Éditions universitaires de Dijon, 2015.

VILAR, Hermínia Vasconcelos - "Episcopal appointments and royal power: theory and practice of an unwritten privilege in medieval Portugal". Imago Temporis. Medium Aevum 11 (2017), pp.

233-254.

VILAR, Hermínia Vasconcelos - "No tempo de Avinhão: Afonso IV e o episcopado em meados de Trezentos”. Lusitania Sacra. $2^{a}$ série, 22 (2010), pp. 149-168.

ZUTSHI, Patrick - "Petitions to the Pope in the Fourteenth Century". in ORMROD, W. Mark, et al. (ed.) - Medieval Petitions: Grace and Grievance. Suffolk: Boydell \& Brewer, 2009, pp. 82-98.

\section{NOTAS}

1. Sobre o processo de constituição e divulgação das Ordenações Afonsinas e sobre a sua organização em cinco livros veja-se DOMINGUES, José - As Ordenações Afonsinas: três séculos de direito medieval [1211-1512]. Sintra: Zéfiro, 2008.

2. Ordenações Afonsinas, $2^{\mathrm{a}}$ ed. Lisboa: Fundação Calouste Gulbenkian, 1998, Livro II, pp. 3 a 156 para todos os acordos. Os capítulos respeitantes a Elvas estão inseridos entre as páginas 61 e 87 . Ainda sobre estes acordos e a sua integração nas Ordenações Afonsinas veja-se CAETANO, Marcello - História Do Direito Português. Fontes- Direito Público (1140-1495). $2^{\text {a }}$ ed. Lisboa: Editorial Verbo, 1985, em especial pp. 538-540.

3. Para o caso inglês veja-se JONES, W. R. - "Bishops, Politics, and the Two Laws: The Gravamina of the English Clergy". Speculum 41:2 (1966), pp. 209-245 e DENTON, J. H. - "The Making of the “Articuli Cleri” of 1316". The English Historical Review 101.400 (1986), pp. 564-595. No caso de Castela atente-se na importância dessas listas realçada por LINEHAN, Peter - The Spanish Church and the Papacy in the Thirteenth Century. Cambridge: University Press, 2005.

4. A itinerância de D. Pedro foi estudada por MACHADO, J. T. Montalvão - Itinerários de El-Rei D. Pedro (1357-1367), Lisboa: Academia Portuguesa de História, 1978. Sobre os locais escolhidos para as reuniões de Cortes entre 1250 e 1490 atente-se no mapa incluído em MARQUES, A. H. de Oliveira e DIAS, João Alves - Atlas Histórico de Portugal e do Ultramar Português. Lisboa: Centro de Estudos Históricos, 2003, p. 110, no qual é visível a escolha exclusiva de Elvas por D. Pedro. A 
representação gráfica dos itinerários descritos pelos diferentes reis a partir de Afonso III e até D. Pedro encontra-se na mesma obra nas páginas 101 a 104.

5. Cortes Portuguesas. Reinado de D. Pedro I (1357-1367). Lisboa: Instituto Nacional de Investigação Científica, 1986.

6. Uma reflexão interessante sobre o papel dos bispos na comunidade política, embora centrada no caso inglês, pode ser encontrada em AMBLER, S. T. - Bishops in the Political Community of England, 1213-1272. Oxford: Oxford University Press, 2017, pp. 12-31. Para o caso francês merece realce a análise feita por TABBAGH, Vincent - Les Évêques dans Le Royaume de France au XIVe Siècle. Dijon: Éditions universitaires de Dijon, 2015.

7. Cortes Portuguesas. Reinado de D. Afonso IV (1325-1357). Lisboa: Instituto Nacional de Investigação Científica, 1982, p. 123.

8. SOUSA, Armindo de - As Cortes Medievais Portuguesas (1385-1490). 2 vols, Porto: Instituto Nacional de Investigação Científica, 1990 em especial pp. 184-189.

9. SOUSA, Armindo de - As Cortes Medievais Portuguesas (1385-1490) ..., vol. I, p. 184 e sobre a participação do clero nas cortes castelhanas: O' CALLAGHAN, Joseph - “The Ecclesiastical Estate in the Cortes of Leon-Castille, 1252-1350'. The Catholic Historical Review LXVII.2 (1981), pp. 185-213 e ARRANZ DE GUZMAN, Ana - "Reconstrucción y verificación de las Cortes castellano-leonesas: la participación del clero”. En La España Medieval 13 (1990), pp. 33-132.

10. MARQUES, José - "Igreja e poder régio". in A Génese do Estado Moderno no Portugal Tardomedievo. Ciclo de conferências. Lisboa: Universidade Autónoma de Lisboa, 1999, pp. 217-256, em especial, pp. 227-228.

11. Cortes Portuguesas. Reinado de D. Pedro I ..., respetivamente p. 17 e p. 19.

12. Cortes Portuguesas. Reinado de D. Pedro I ..., p. 19.

13. Cortes Portuguesas. Reinado de D. Pedro I ..., p. 26.

14. Cortes Portuguesas. Reinado de D. Pedro I ..., p. 26.

15. VILAR, Hermínia Vasconcelos - "Episcopal appointments and royal power: theory and practice of an unwritten privilege in medieval Portugal”. Imago Temporis. Medium Aevum 11 (2017), pp. 233-254.

16. Oliveira Marques frisava-o em 1987 aquando da publicação do IV volume da Nova História de Portugal, argumentando que D. Pedro tinha perseguido o clero, sendo os capítulos de 1361 um reflexo das queixas que o clero dirigia contra o rei, senhores e mesmo contra os concelhos protegidos por D. Pedro. MARQUES, A.H. de Oliveira - Portugal na Crise dos séculos XIV e XV. Vol. IV. Nova História de Portugal. Lisboa: Estampa, 1987, p. 507.

17. De entre os reis da Primeira Dinastia, D. Pedro é talvez o monarca sobre cujo governo mais incidem os problemas decorrentes da escassez documental. A sobrevivência de um único livro de chancelaria é um limite claro ao conhecimento desta governação e nem mesmo o facto deste livro incluir documentação oriunda dos dez anos do reinado permite ultrapassar, de forma clara, as consequências dessa escassez documental. E se bem que a Crónica de D. Pedro constitua um elemento adicional de inegável importância para o conhecimento destes anos, a verdade é que a valorização de determinados acontecimentos tem igualmente limitado ou enviesado a reflexão sobre este período.

18. Chancelarias Portuguesas. D. Pedro I, $\mathrm{n}^{\circ} 538$, p. 219.

19. Chancelarias Portuguesas. D. Pedro I, $\mathrm{n}^{\circ}$ 547, pp. 234-235.

20. ANTT, Cabido da Sé de Lamego, maço 3 de doações, cartas e mercês régias, no 8 e 10 .

21. Chancelarias Portuguesas. D. Pedro I, no 558, p. 241.

22. A nomeação do seu sucessor data de 18 de Junho de 1361 e a sua transferência terá possivelmente sido autorizada em 16 de Junho de 1361. EUBEL, Conradus - Hierarchia Catholica Medii Aevi sive Summorum Pontificum, S.R.E. Cardinalium, Ecclesiarum Antistitum 
Series: ab Anno 1198 usque ad annum 1431 perducta:et Documentis tabularii praesertim Vaticani collecta, digesta. Monasterii, 1935-1978, p. 144.

23. Chancelarias Portuguesas. D. Pedro I, $\mathrm{n}^{\circ} 554$ e 555, pp. 237-238. Em carta de 1341, Afonso IV reconhecia ao arcebispo de Braga, então Gonçalo Pereira, vários privilégios, entre os quais a capacidade de nomear tabeliães, embora tenha ressalvado a correição entregue ao rei. Com esta carta, Afonso IV fechava o conflito iniciado alguns meses antes com D. Gonçalo Pereira, arcebispo cujo percurso foi estudado por COELHO, Maria Helena - "O arcebispo D. Gonçalo Pereira: um querer, um agir”. in IX Centenário da Dedicação da Sé de Braga. Congresso Internacional. Actas. Vol. II/ 1. A Catedral de Braga na História e na Arte (séculos XII-XIX). Braga: Universidade Católica Portuguesa, Faculdade de Teologia, Cabido Metropolitano e Primacial de Braga, 1990, pp, 389-462. Ainda sobre este conflito, VILAR, Hermínia Vasconcelos - "No tempo de Avinhão: Afonso IV e o episcopado em meados de Trezentos". Lusitania Sacra, $2^{\mathrm{a}}$ série, 22 (2010), pp. 149-168, COSTA, Adelaide Millán - "Comunidades urbanas de senhorio eclesiástico; a divergente experiência das Cidades do Porto e de Braga". in Estudos em Homenagem ao Prof. Dr. José Marques. Vol. I. Porto: FLUP, 2006, pp. 77-85.

24. Chancelarias Portuguesas. D. Pedro I, $\mathrm{n}^{\circ}$ 552, pp. 236-237.

25. Chancelarias Portuguesas. D. Pedro I, $\mathrm{n}^{\circ}$ 553, p. 237.

26. Uma reflexão recente e sugestiva sobre as relações entre rei e Igreja no que se refere, em particular, a Portugal e Castela na primeira metade do século XIV é a de LINEHAN, Peter - At the Edge of Reformation: Iberia before the Black Death. New York: Oxford University Press, 2019, obra na qual algumas destas questões e protagonistas são analisados. O chamado "chamamento geral" datado da primeira metade de 1334 é conhecido a partir das cartas que resultaram das confirmações e inquirições feitas a partir da apresentação dos documentos por parte dos detentores das jurisdições, tal como é realçado por MARQUES, José - "D. Afonso IV e as jurisdições senhoriais". in Actas das II Jornadas Luso-Espanholas de História Medieval. Vol. IV. Porto: INIC, 1990, pp. 1527-1566 e SOUSA, Bernardo Vasconcelos e - D. Afonso IV. Rio de Mouro: Círculo de Leitores: 2005, p. 102 e seguintes.

27. cosTA, Adelaide Millán da - "Comunidades urbanas de senhorio eclesiástico" ..., pp. 77-85; CRUZ, António - "Os bispos senhores da cidade. II - de D. Pedro Salvadores a D. Vasco Martins". in PERES, Damião e CRUZ, António (eds.) - História da cidade do Porto. Vol.I. Porto: Portucalense Editora, 1962, pp. 184-248.

28. Chancelaria de D. Pedro I, $\mathrm{n}^{\mathrm{o}}$ 130, p. 57. Também em Junho de 1361 um novo acordo é estabelecido entre o rei e bispo. ANTT, Gavetas, Gaveta XIII, maço 5, oㅡ 4. Monsenhor José Augusto Ferreira refere ainda uma outra confirmação de jurisdição datada de 1359 e referente aos coutos de Paranhos, Crestuma, Loriz e Régua e uma carta de restituição de propriedades, anteriormente usurpadas, datada de 1360. FERREIRA, Monsenhor J. Augusto - Memórias Archeológico-Históricas da cidade do Porto. Braga: Livraria Cruz, 1923, p. 375.

29. FREITAS, Eugénio Cunha e - "Os bispos senhores da cidade. III- de D. Pedro Afonso a D. Gil Alma”. in PERES, Damião e CRUZ, António (eds.) - História da cidade do Porto. Vol. I, ..., pp. 249-297. Nesse sentido vai também a opinião de Cristina Pimenta numa perspectiva ampla sobre as relações com o clero. PIMENTA, Cristina - D. Pedro I. Rio de Mouro: Círculo de Leitores, 2005, pp. 126-127. Em Janeiro de 1360, D. Pedro pede ao papa a confirmação do acordo estabelecido entre Afonso IV e o Bispo do Porto, argumentando que o acordo não teria seguido os trâmites normais em virtude da morte do bispo, referindo-se então a Pedro Afonso. COSTA, António Domingues de Sousa (ed.) - Monumenta Portugaliae Vaticana. I - Súplicas dos pontificados de Clemente VI, Inocêncio VI e Urbano V. Braga - Porto: Editorial Franciscana, 1968, p. 362.

30. Chancelaria de D. Pedro I, no 553, p. 237.

31. Chancelaria de D. Pedro I, no 112, p. 50.

32. Chancelaria de D. Pedro I, no 181, pp. 70-71.

33. Chancelaria de D. Pedro I, nํㅜ 310, pp. 113-116. 
34. Chancelaria de D. Pedro I, nำ 438, p. 174.

35. É o que parece acontecer com o Porto, Coimbra e Viseu e com as cartas genéricas de confirmação exaradas logo em 1357. Chancelaria de D. Pedro I, no 130, p. 57; no 161, p. 63 e ํo 236, p. 84.

36. Chancelaria de D. Pedro I, $\mathrm{n}^{\circ}$ 408, pp. 162-163.

37. O conjunto destas cartas, existente no Arquivo Municipal de Lisboa foi publicado, recentemente, por LOUREIRO, Sara - "O conflito entre D. Afonso IV e o infante D. Pedro (1355-1356)." Cadernos do Arquivo Municipal, $1^{\text {a }}$ série, 7 (2003), pp. 8-62. Entre outras publicações, refira-se a realizada em Livro I de Místicos de Reis, Livro II dos Reis D. Dinis, D. Afonso IV D. Pedro Documentos para a História da Cidade de Lisboa. Lisboa: Câmara Municipal de Lisboa, 1947.

38. SOUSA, Bernardo Vasconcelos e - D. Afonso IV ..., pp. 168-173. Ainda deste autor, ver "A Guerra Civil de 1355". in A Guerra e a sociedade na Idade Média. Actas das VI Jornadas Luso-Espanholas de Estudos Medievais, 2 vols. Coimbra: Sociedade Portuguesa de Estudos Medievais, 2009, vol. II, pp. 393-407, onde analisa detalhadamente as fases deste processo de estabelecimento de acordos.

39. $O$ contexto peninsular subjacente à morte de Inês de Castro foi analisado na recente biografia dedicada a esta figura da autoria de COSTA, Adelaide Pereira Millán da - "As mulheres de D. Pedro I. Branca de Castela, Constança Manuel e Inês de Castro." in MENINO, Vanda Lourenço; COSTA, Adelaide Lopes Pereira Millán - A rainha, as infantas e a aia: Beatriz de Castela, Branca de Castela, Constança Manuel, Inês de Castro. Lisboa: Círculo de Leitores, 2012, em especial, pp. 339-457.

40. Em Dezembro de 1355, Inocêncio VI dirigia uma carta ao rei de Portugal, ainda Afonso IV, e pedia-lhe que não transferisse para o actual bispo os rancores que tinha para com o anterior, Pedro Afonso, numa clara alusão aos problemas havidos sobre o senhorio do Porto. Innocent VI (1352-1362). Lettres secrètes et curiales, publiées ou analysées par Pierre Gasnault. Tome III, fascicule IV. Paris: Éd. de Boccard, 1968, p. 160.

41. SOUSA, Bernardo Vasconcelos e - D. Afonso IV ..., p. 172.

42. EUBEL, Conradus - Hierarchia Catholica Medii Aevi ..., p. 144 para Guilherme de La Garde, nomeado a 27 de Julho de 1349 e p. 406 para Afonso Pires do Porto, nomeado por carta de 26 de Outubro de 1355.

43. EUBEL, Conradus - Hierarchia Catholica Medii Aevi ..., pp. 236 (Évora), 291 (Lamego), 452 (Silves) e 531 (Viseu). O intervalo de nomeações vai de Junho de 1349 a Fevereiro de 1350, com a excepção de João Gomes, confirmado em Novembro de 1356.

44. EUBEL, Conradus - Hierarchia Catholica Medii Aevi ..., pp. 196 (Coimbra), 235 (Guarda) e 507 (Lisboa).

45. EUBEL, Conradus - Hierarchia Catholica Medii Aevi ..., p, 235 e CASTRO, José Osório da Gama e, Diocese e Districto da Guarda. Porto: [s.e.], 1902, pp. 414-416 e GOMES, Josué Pinharanda - História da Diocese da Guarda, Braga: [edição de autor], 1981, p. 153.

46. São eles Lourenço Rodrigues, identificado por Mário Farelo como Lourenço Martins de Barbudo, e Pedro Gómez Barroso. O primeiro é transferido em 1358 e permanecerá em Lisboa até 1364. O segundo vai para Lisboa em 1364, onde permanece até 1369 e à sua transferência para Sevilha. LEITÃo, André de Oliveira - "Lourenço Rodrigues (ou Lourenço Martins de Barbudo)". in FONTES, João Luis (dir); GOUVEIA, António Camões; ANDRADE, Maria Filomena; FARELO, Mário (coord.) - Bispos e Arcebispos de Lisboa. Lisboa: Livros Horizonte, 2018, pp. 329-344 e DIAZ IBÁNEZ, Jorge; FARELO, Mário - "Pedro Gómez Barroso, o jovem". in FONTES, João Luis (dir); GOUVEIA, António Camões; ANDRADE, Maria Filomena; FARELO, Mário (coord.) - Bispos e Arcebispos de Lisboa ..., pp. 345-351.

47. E poucos meses depois será transferido para Braga. Uma síntese dos percursos destes bispos de Coimbra da segunda metade do século XIV encontra-se em MORUJÃO, Maria do Rosário "Bispos em tempo de guerra: os prelados de Coimbra na segunda metade do século XIV". in A 
Guerra e a sociedade na Idade Média. Actas das VI Jornadas Luso-Espanholas de Estudos Medievais. Vol. II, ..., pp. 539-550 e mais recentemente em LEITÃO, André de Oliveira; NORTE, Armando - "Vasco Rodrigues". in Bispos e Arcebispos de Lisboa ..., pp. 361-379.

48. Alguns destes prelados pertenciam a linhagens que se caracterizam pela continuidade do serviço eclesiástico como é o caso de Afonso Pires, bispo do Porto. Sobre este prelado SARAIVA, Anísio Miguel de Sousa - "O processo de inquirição do espólio de um prelado trecentista: D. Afonso Pires, bispo do Porto (1359-1372)." Lusitania Sacra, 2ª série, 13-14 (2001-2002), pp. 197-228.

49. HOMEM, Armando Luís de Carvalho - O Desembargo Régio (1320-1433). Porto: Instituto Nacional de Investigação Científica, Centro de História da Universidade do Porto, 1990, pp. 176-179 e do mesmo autor "Subsídios para o estudo da administração central no reinado de D. Pedro I". in HOMEM, Armando Luís de Carvalho - Portugal Nos Finais Da Idade Média: Estado, Instituições, Sociedade Política. Lisboa: Livros Horizonte, 1990, pp. 63-107. Um levantamento de alguns dos mais próximos colaboradores do rei foi realizado mais recentemente por MUXAGATA, Ana Filipa Coelho - A Corte de D. Pedro I (1320-1367). Lisboa: Universidade de Lisboa, 2019. Dissertação de Mestrado.

50. HOMEM, Armando Luís de Carvalho - O Desembargo Régio (1320-1433) ..., pp. 315-317. Para um período posterior ver o trajecto de Vicente Domingues sintetizado na pp. 391-392.

51. Fernão Lopes escreve mesmo que o rei afirmava que "dia que o rrei não dava não devia seer avudo por rrei", realçando assim a centralidade do rei enquanto distribuidor de graça. LOPES, Fernão - Crónica de D. Pedro. Lisboa: Imprensa Nacional-Casa da Moeda, 2007, p. 8.

52. LOPES, Fernão - Crónica de D. Pedro ..., pp. 125-127 e ARNAUT, Salvador Dias - A Crise Nacional Dos Fins Do Século XIV. I - A Sucessão de D. Fernando. Lisboa: Imprensa de Coimbra, 1960, pp. 82-84.

53. A este nível, vale a pena realçar o número relativamente importante de súplicas dirigidas por D. Pedro ao papa no decurso do seu reinado. Súplicas que contemplam vários eclesiásticos e seus colaboradores, como é o caso de Guilherme de Piloti, Afonso Domingues de Linhares, Gonçalo Vasques, Lourenço Esteves filho de Lourenço Esteves, um membro do Desembargo régio e do Conselho do rei, Vasco Gonçalves, João Eanes, Gomes Lourenço do Avelal. Identificados em alguns casos como comensais do rei, seus servidores ou familiares, esta lista reflecte o papel do rei como intermediário e como elemento de pressão junto ao Papado na obtenção de favores para eclesiásticos que eram seus protegidos, mas também a importância e a amplitude das redes que atravessam e unem leigos e eclesiásticos na órbita régia e nos círculos administrativos. Lógicas e articulações que matizam o impacto da ausência dos eclesiásticos do desembargo régio e o que esta ausência pode indicar de diminuição da influência dos clérigos. COSTA, António Domingues de Sousa (ed.) - Monumenta Portugaliae Vaticana. I - Súplicas dos pontificados de Clemente VI, Inocêncio VI e Urbano V. Braga- Porto: Editorial Franciscana, 1968. Sobre as implicações e caracteristicas destas petições no século XIV vejam-se as interessantes reflexões de ZUTSHI, Patrick - "Petitions to the Pope in the Fourteenth Century". in ORMROD, W. Mark, et al. (ed.) - Medieval Petitions: Grace and Grievance. Suffolk: Boydell \& Brewer, 2009, pp. 82-98.

\section{RESUMOS}

Em 1361 D. Pedro reunia Cortes em Elvas, lugar excêntrico no quadro do que até então tinham sido os lugares escolhidos para essas reuniões. Das actas dessas Cortes ressalta um conjunto de 
capítulos, apresentado pelo clero português, e coligidos, mais tarde, nas Ordenações Afonsinas. Tidos como um reflexo da permanência de problemas anteriores, o conteúdo destes capítulos bem como o contexto da sua apresentação merecem uma análise mais detalhada, tendo em linha de conta o quadro mais amplo das relações clero - realeza em meados do século XIV em Portugal. O questionário subjacente a esta análise tem assim em linha de conta, por um lado, as implicações e condicionalismos do recurso à apresentação de queixas por parte do clero ao rei ou ao papa e, por outro, a importância que a crise de 1355-56, bem como as sequelas da política afonsina, podem ter tido nestes primeiros anos do reinado de D. Pedro.

In 1361 D. Pedro gathered Cortes in Elvas, a very uncommon place if we take in account the places chosen for these meetings. One of things most remarkable of this Cortes was the presentation of a list of grievances by the Portuguese clergy to the king. List that was, several decades after, collected in the Ordenações Afonsinas.

Normally seen as a reflection of the persistence of previous problems between clergy and kings, the content and context of these grievances deserve a more detailed analysis. In this article, we intend to draw attention to the implications of the frequent presentation of grievances by the clergy to the king or pope and also to the importance of the crisis of $1355-1356$ in the first years of governance of D. Pedro.

ÍNDICE

Keywords: Kingship, “Cortes” of 1361, Bishops, Grievances

Palavras-chave: Realeza, Cortes 1361, Bispos, Agravos

\section{AUTOR}

\section{HERMÍNIA VASCONCELOS VILAR}

Universidade de Évora, CIDEHUS - Centro Interdisciplinar de História, Culturas e Sociedades 7000-803 Évora, Portugal. hmav@uevora.pt. https://orcid.org/0000-0003-3300-8335. 